\title{
Heat Treatments and Thermomechanical Cycling Influences on the R-Phase in Ti-Ni Shape Memory Alloys
}

\author{
Cezar Henrique Gonzalez $z^{\mathrm{a}}$, Carlos Augusto do Nascimento Oliveira, ${ }^{\mathrm{a},}$, Euclides Apolinário Cabral de Pina ${ }^{\mathrm{a}}$, \\ Severino Leopoldino Urtiga Filho ${ }^{\text {a }}$ Oscar Olimpio de Araújo Filho ${ }^{\text {a }}$ Carlos José de Araújo ${ }^{\mathrm{b}}$ \\ ${ }^{a}$ Mechanical Engineering Department, Federal University of Pernambuco - UFPE, \\ Av. Acadêmico Hélio Ramos, s/n, Cidade Universitária, CEP 50740-530, Recife, PE, Brasil \\ ${ }^{\mathrm{b}}$ Mechanical Engineering Department, Federal University de Campina Grande - UFCG, \\ Av. Aprígio Veloso, 882, CP 10069, CEP 58109-970, Campina Grande, PB, Brasil
}

Received: December 14, 2009; Revised: June 23, 2010

\begin{abstract}
This article studies changes observed on the R-phase thermoelastic behavior in a near-equiatomic Ti-Ni shape memory alloy. Three kinds of procedures have been performed: different treatments, thermomechanical cycling under constant loading in shape memory helical springs and thermal cycling in as-treated and trained samples. Several heat treatments were carried out to investigate evolution of the R-phase by differential scanning calorimetry (DSC). A heat treatment was chosen on which R-phase is absent. Shape memory springs were produced and submitted to a training process in an apparatus by tensioning the springs under constant loading. Thermal cycling in DSC was realized in as-treated and trained samples. Several aspects of one-step (B2 $\rightarrow$ B19') and two-steps (B2 $\rightarrow \mathrm{R} \rightarrow \mathrm{B} 19^{\prime}$ ) martensitic transformations and R-phase formation and their evolution during tests were observed and discussed.
\end{abstract}

Keywords: shape memory spring, heat treatments, $R$-phase, ti-ni alloys and thermoelastic properties

\section{Introduction}

Mechanical properties of Ti-Ni alloys are very interesting for the development of smart actuators manufactured from this special kind of non-conventional material. In many technical applications these actuators need to generate forces and to avoid the degradation of the shape memory effect caused by the martensitic stabilization processes ${ }^{1-3}$. These characteristics allow its utilization in various domains of knowledge, for example: space reduction (miniaturization), human movement simulation (robot), medical applications and others. In the smart sensor/actuators, helical spring shapes are more interesting because of their deflection and the possibility of forces generation, as for example in endoscope activated by a shape memory spring that makes the surgery with less or minimum evasion to the patient $t^{2,3}$.

Several heat treatments were investigated in order to modify the transformation temperatures of alloys object of this study. The objectives went to dislocate the critical temperatures for near room temperature and to avoid the R-phase formation, very common in Ti-Ni alloys submitted to cold work. Despite the several studies of understanding about the R-phase formation in the Ti-Ni alloys, there are yet few applications that could use the narrow ranges of shape recovery presented by this phase. Several research indicate that the presence of the R-phase during martensitic transformation (two-steps, $\mathrm{B} 2 \rightarrow \mathrm{R} \rightarrow \mathrm{B} 19^{\prime}$, where $\mathrm{B} 2$ and B19` represent crystalline structures of the austenitic and martensitic phases, respectively) because matrix phase hardened, hindering the generation of the stress fields associated to dislocation reconfiguration process that facilitate the two-way shape memory effect. The main advantage of suppressing the R-phase formation is to the attain an uniformity in the stress fields, proportioning a better efficiency of the shape memory effect ${ }^{4,5}$. Thermoelastic studies on the sma-springs allows to study the R-phase behavior (R) and martensitic phases (M), during thermal cycles with and without tensile loads application.
This study was developed in a wire with $0.89 \mathrm{~mm}$ in diameter of a near-equiatomic Ti-Ni alloy. Samples of this wire were submitted for three tests: different heat treatments by calorimetry, thermomechanical cycling under constant loading in shape memory helical springs and thermal cycling by calorimetry in the as-treated and trained samples. Wire was drawn to manufacture helical springs with $6 \mathrm{~mm}$ in diameter and four active coils.

\section{Experimental Procedure}

A cold-drawn shape memory alloy wire of Ti-Ni with nearequiatomic composition and diameter of $0.89 \mathrm{~mm}$ was used to manufacturer helical springs. Procedure is demonstrated in the references 1 and 6. Shape memory springs have $6.0 \mathrm{~mm}$ external diameter and $4.2 \mathrm{~mm}$ internal diameter and four active coils.

Initially, a study were realized in as-received specimens by differential scanning calorimetric method (DSC) to determine martensitic transformation temperatures (martensite start- $M_{s}$, martensite finish- $\mathrm{M}_{\mathrm{f}}$, austenite start- $\mathrm{A}_{\mathrm{s}}$, austenite finish- $\mathrm{A}_{\mathrm{f}}$, rhombohedral start or R-phase start- $\mathrm{R}_{\mathrm{s}}$ and $\mathrm{R}$-phase finish- $\mathrm{R}_{\mathrm{f}}$ after, samples was submitted for several heat treatments to verify the behavior of the critical temperatures. Thermal cycles in DSC method were performed in a range between -60 and $90{ }^{\circ} \mathrm{C}$ at a rate constant of $10{ }^{\circ} \mathrm{C} / \mathrm{min}$. Specimens was homogenized at 400,500 and $600{ }^{\circ} \mathrm{C}$ followed by quench in water at $25^{\circ} \mathrm{C}$ and the ageing times applied were 1, 2, 4, 8, 12 and 24 hours. The treatment chosen for subsequent tests (cases: spring samples and thermal cycling without loading samples) was homogenization at $500{ }^{\circ} \mathrm{C}$ for 24 hours followed by quench in water at $30{ }^{\circ} \mathrm{C}$. In this treatments, the transformation temperatures were above room temperature and the R-phase seems to have been suppressed. 
Shape memory springs (SMS) was submitted to thermomechanical cycles in a mass-pulley special apparatus described in the references 6 and 7. This apparatus is constituted by a programmable silicon oil bath, linear variation displacement transducer (LVDT), thermocouple and a data acquisition system. In this apparatus, the SMS were submitted 50 thermal cycles under constant loads of $70,105,170$ and $200 \mathrm{MPa}$ and temperature interval between 25 and $140{ }^{\circ} \mathrm{C}$. The heating and cooling rate are estimated in 10 and $6{ }^{\circ} \mathrm{C} / \mathrm{min}$, respectively.

From data acquisitions, deformation vs. temperature and temperature vs. number of cycles curves were plotted, and shape memory effect thermoelastic properties were determined. Figure 1 shows a typical curve and the procedure to determine critical transformation temperatures under stress $\left(\mathrm{A}_{\mathrm{S}}, \mathrm{A}_{\mathrm{F}}, \mathrm{M}_{\mathrm{S}}\right.$ and $\left.\mathrm{M}_{\mathrm{F}}\right)$ using the tangent method, thermoelastic strain $\left(\varepsilon_{t}=\right.$ difference between the strain at low and high temperatures), thermal hysteresis (Ht), and vertical displacement of hysteresis loops $(\mathrm{X})^{6}$.

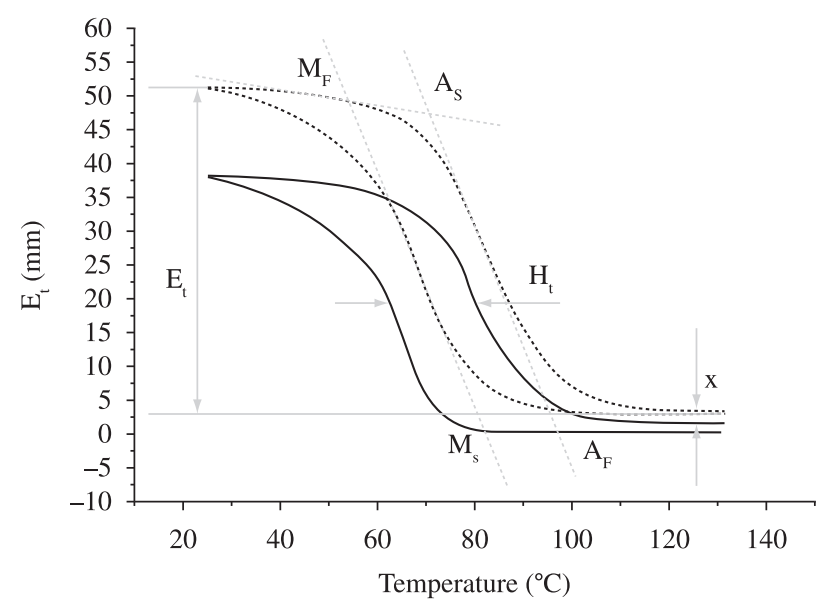

Figure 1. Characteristic parameters of the shape memory effect in a strain vs. temperature curve.

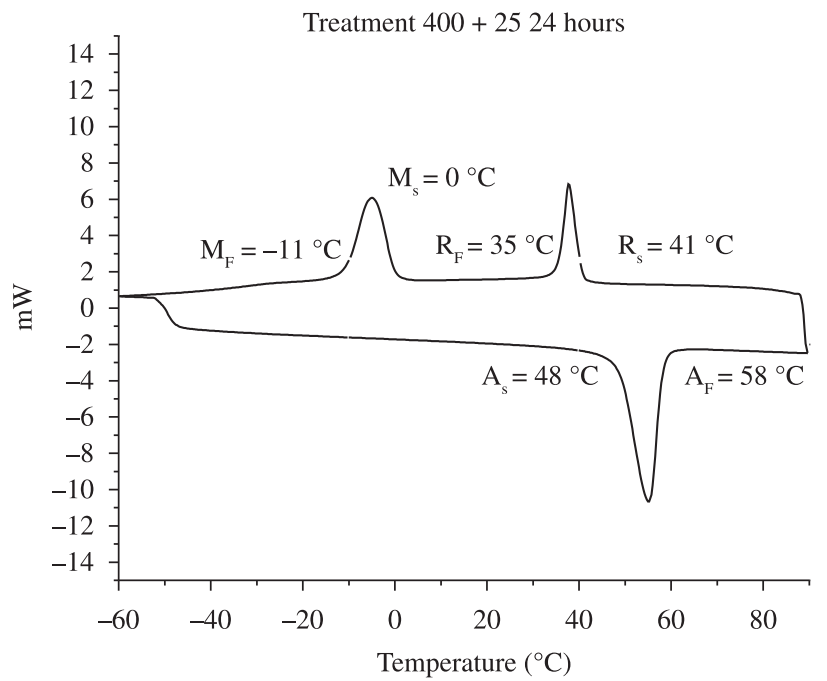

(a)

\section{Results}

\subsection{Study calorimetrical of heat treatments influences in phase transformations}

The objective of this investigation is to observe the changes in transformation temperatures and enthalpies obtained from heat treatments procedures. Samples were heat treated at 400, 500 and $600{ }^{\circ} \mathrm{C}$ with homogenization times of $1,2,4,8,12$ and 24 hours and followed by quench in water at $25^{\circ} \mathrm{C}$. For all samples heat treatment at $400{ }^{\circ} \mathrm{C}$ has showed the normal sequence of phase transformation in the near-equiatomic Ti-Ni wire: $\mathrm{B} 2 \rightarrow \mathrm{R} \rightarrow \mathrm{B} 19$ '. This result is presented in Figure 2a. During heating, the inverse transformation to occurs in an alone step (B19' $\rightarrow$ B2). The sum of enthalpies of exothermic heat flow peaks ( $\mathrm{R}$ and martensitic phases, $\Delta \mathrm{H}_{\mathrm{C}}=19.25 \mathrm{~J}_{\mathrm{g}} \mathrm{g}^{-1}$ ) is very closed for enthalpy of endothermic heat flow peak (austenitic phase, $\Delta \mathrm{H}_{\mathrm{H}}=21.03 \mathrm{~J}_{\mathrm{g}} \mathrm{g}^{-1}$ ). In the samples heat treated at $600{ }^{\circ} \mathrm{C}$ haven't showed R-phase, transformation's enthalpies are of about 20.64 J.g ${ }^{-1}$, as shown in Figure 2b. Other observation for this treatment is stabilization of critical transformation temperatures and enthalpies values independently of ageing time.

Figure 3 show calorimetrical curves for samples heat treated at $500{ }^{\circ} \mathrm{C}$ during six homogenization times. This figure shows evolution of the $\mathrm{R}$ and martensitic phases where peaks tend to approach. From 12 hours of heat treatment theses peaks form practically one alone peak, but with a much larger hysteresis. Changes presented in the calorimetrical curves have been investigated in the literature and two principal causes are appointed. Near-equiatomic Ti-Ni shape memory alloys but lightly rich in nickel can during heat treatment at elevated temperatures to form precipitates such as $\mathrm{Ti}_{3} \mathrm{Ni}_{4}, \mathrm{Ti}_{2} \mathrm{Ni}_{3}$ and $\mathrm{TiNi}_{3}{ }^{8-10}$. These precipitates make martensitic transformation more easier (increase of $\mathrm{M}_{\mathrm{s}}$ in Figure 3) because they act as preferential sites for nucleation of reaction, inhibiting and/or suppressing the appearance of the R-phase. Precipitations occur from diffusional processes which involve changes in chemical composition, modifying transformation temperatures of such a way that increase critical temperatures, in case of the Ni-rich alloys ${ }^{5,11-13}$.

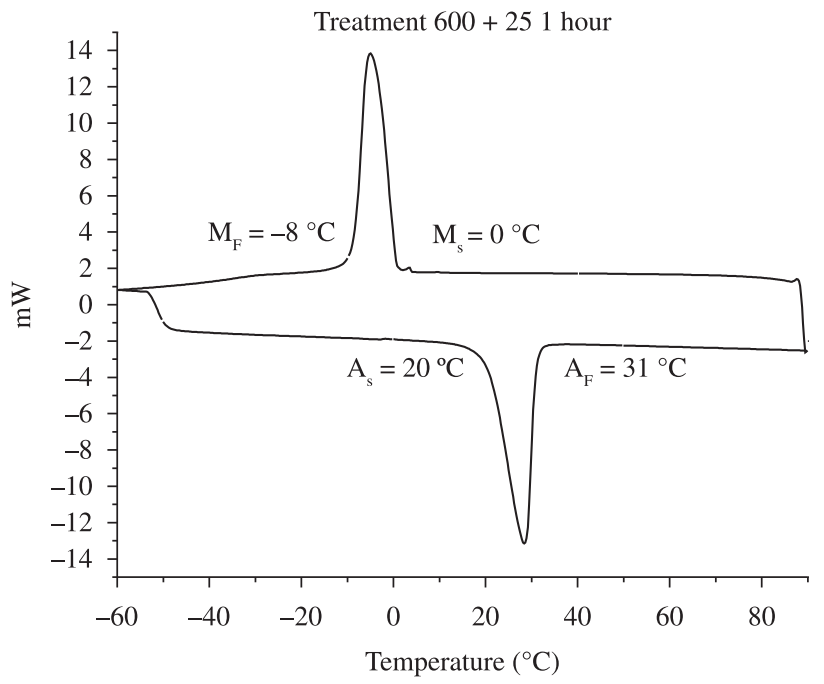

(b)

Figure 2. Calorimetrical curves: a) Sample heat treated at $400{ }^{\circ} \mathrm{C}$ for 24 hours and b) Sample heat treated at $600{ }^{\circ} \mathrm{C}$ for 1 hour. 


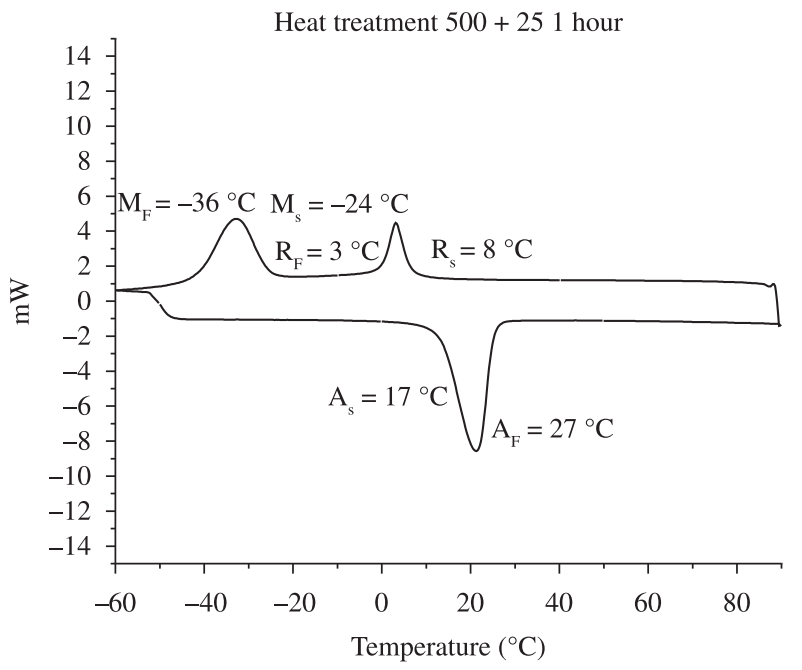

(a)

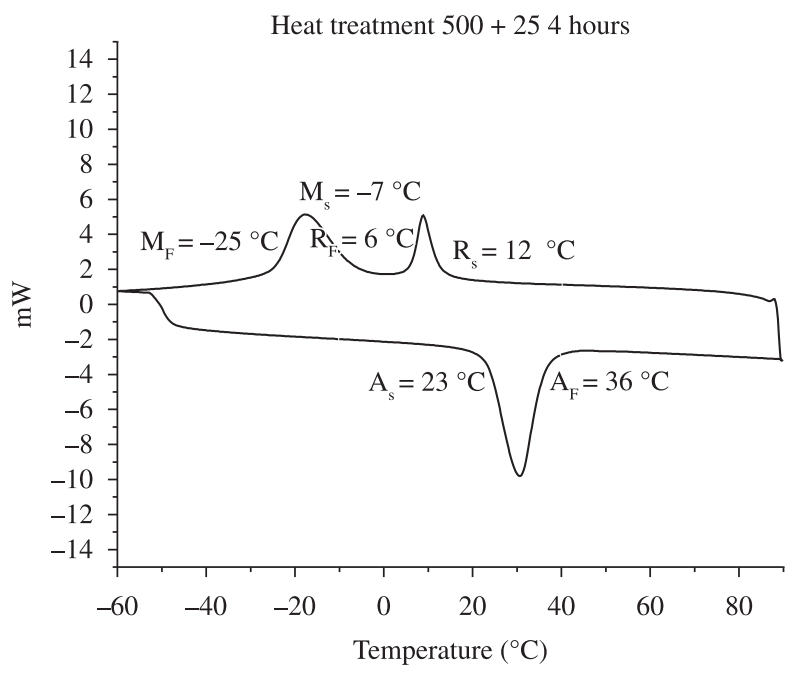

(c)

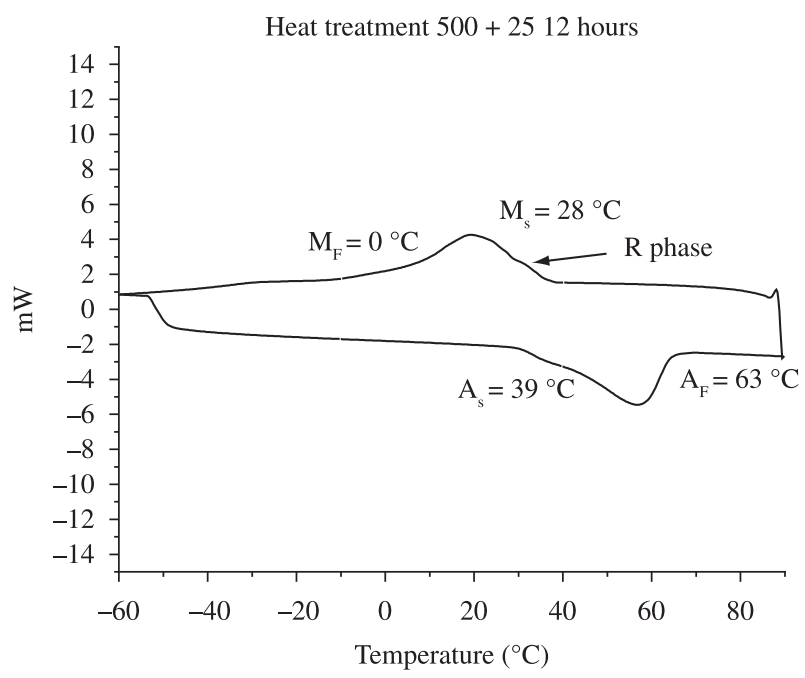

(e)

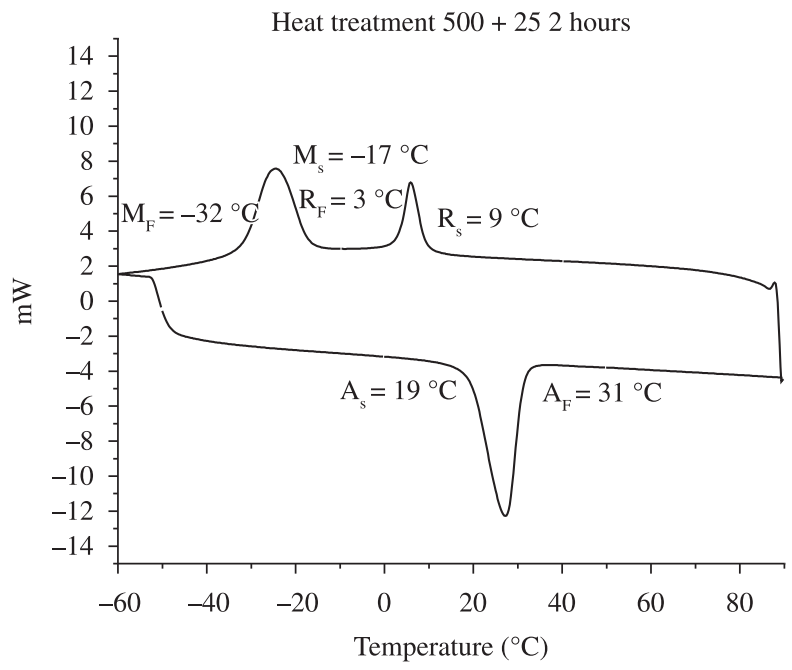

(b)

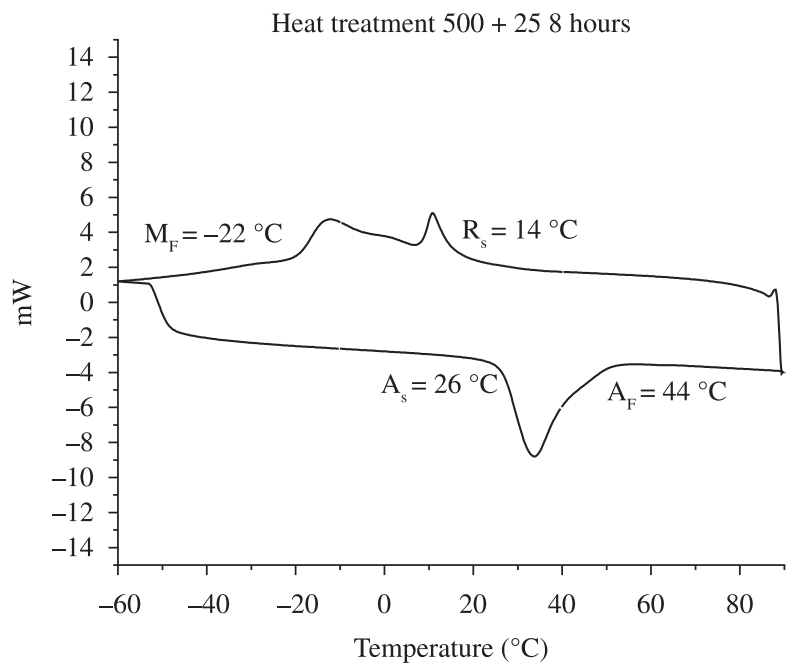

(d)

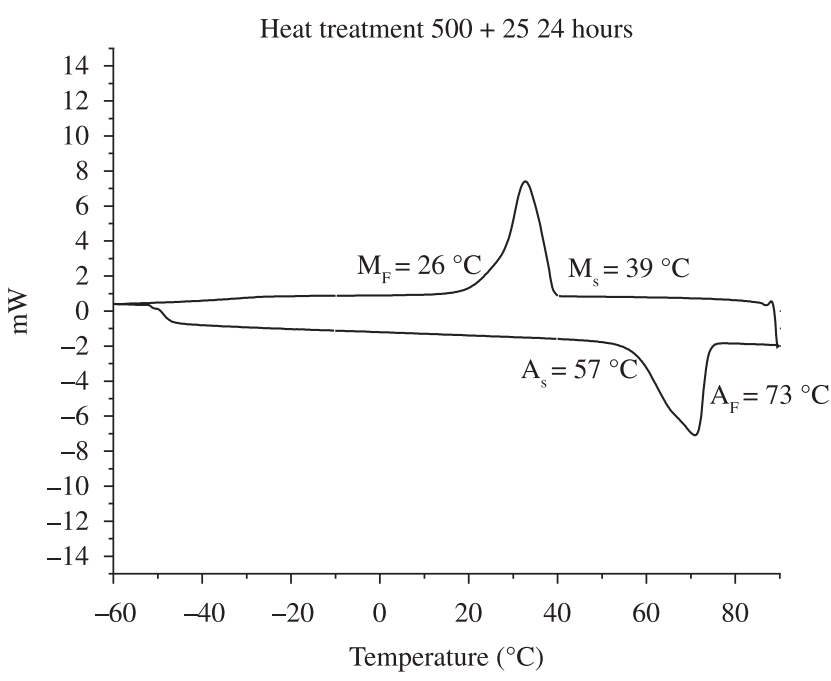

(f)

Figure 3. Calorimetrical curves for samples heat treated at $500{ }^{\circ} \mathrm{C}$ : a) 1 hour; b) 2 hours; c) 4 hours; d) 8 hours; e) 12 hours; and f) 24 hours. 
A second important factor is about deformation stage or dislocation density configurations. This factor depends of the fabrication process, thermomechanical treatments and others. Normally alloys with high dislocation densities present two peaks that correspond to $\mathrm{R}$ and martensitic phases ${ }^{8,12}$. Wires utilized in this work were obtained by cold-drawn process, resulting in a material with high dislocation density.

From curves of Figure 3 is observed during cooling the appearance of multiple peaks or a two-step transformation (Austenite $\rightarrow$ R-phase $\rightarrow$ Martensite). Increasing anneal time, this two-step transformation changes gradually. The R-phase peak temperatures and enthalpies remain practically unchangeable, but martensitic phase peak temperatures increase and hysteresis present a widening. In a first moment, precipitation reactions must to be responsible by the critical temperatures increase due to modifications localized in the chemical compositions. On the other hand, recuperation and recrystallization processes (variation of dislocation density and grain growth) leads changes in the calorimeter curves, showing a decrease in hysteresis and an apparent elimination of the R-phase, In this case the martensitic transformation consisted in a single-step (Austenitie $\rightarrow$ Martensite) ${ }^{5,7,14,15}$.

Samples heat treated at $600^{\circ} \mathrm{C}$ present an one-step transformation. However, shape memory springs produced using this treatment are more rigid than those treated at $500{ }^{\circ} \mathrm{C}$. Apparently, the presence of precipitates difficult the movement of the martensite variants. This behavior appears to be similar when the increase of precipitates are blocking the dislocations, producing hardening of material. Thus, treatment at $500{ }^{\circ} \mathrm{C}$ for 24 hours was chosen for thermomechanical tests.

\subsection{Thermomechanical tests}

Thermomechanical cycles were realized in the SMS to determinate thermoelastic properties of martensitic transformation under constant traction loads. Figure 4 show strain-temperature curves for SMS submitted to constant shear stress at 70, 105, 170 and $200 \mathrm{MPa}$. These curves shown that critical temperatures

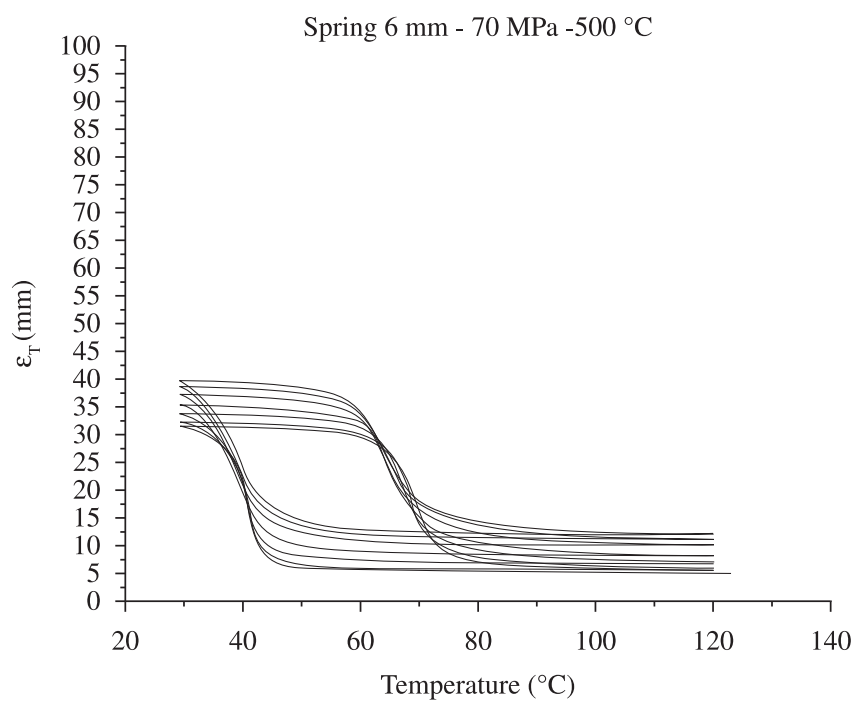

(a)

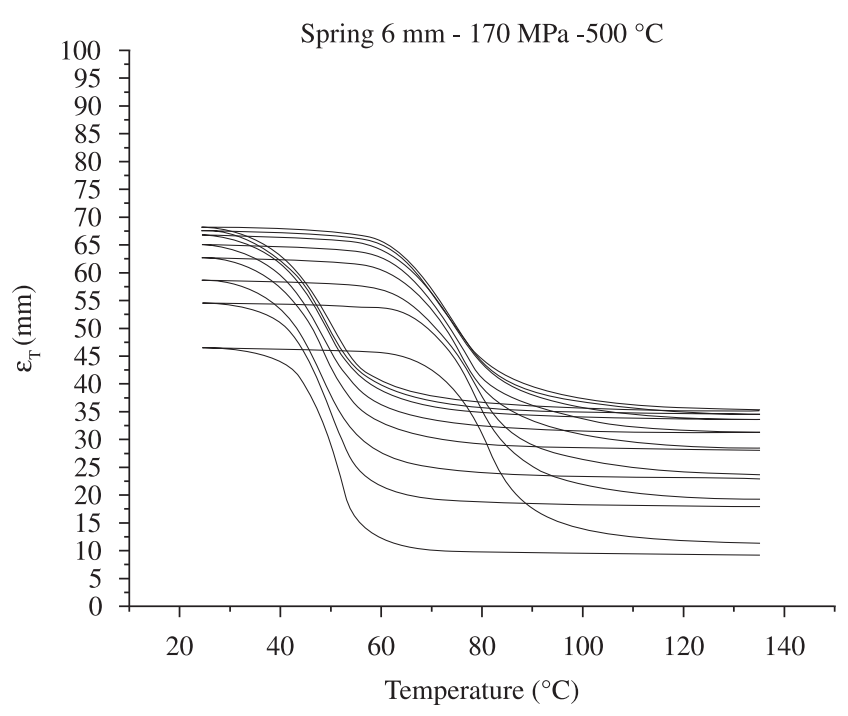

(c)

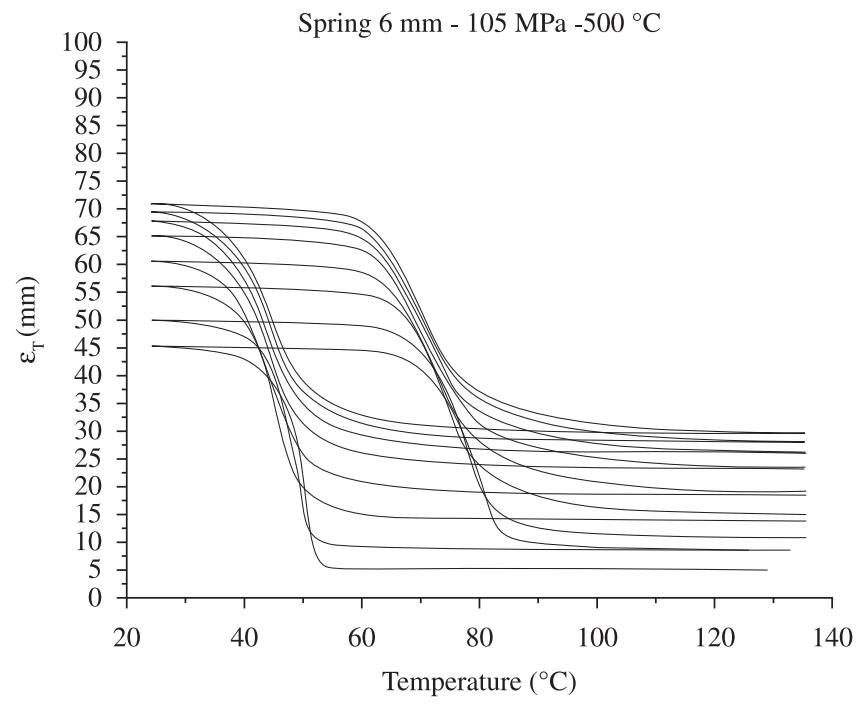

(b)

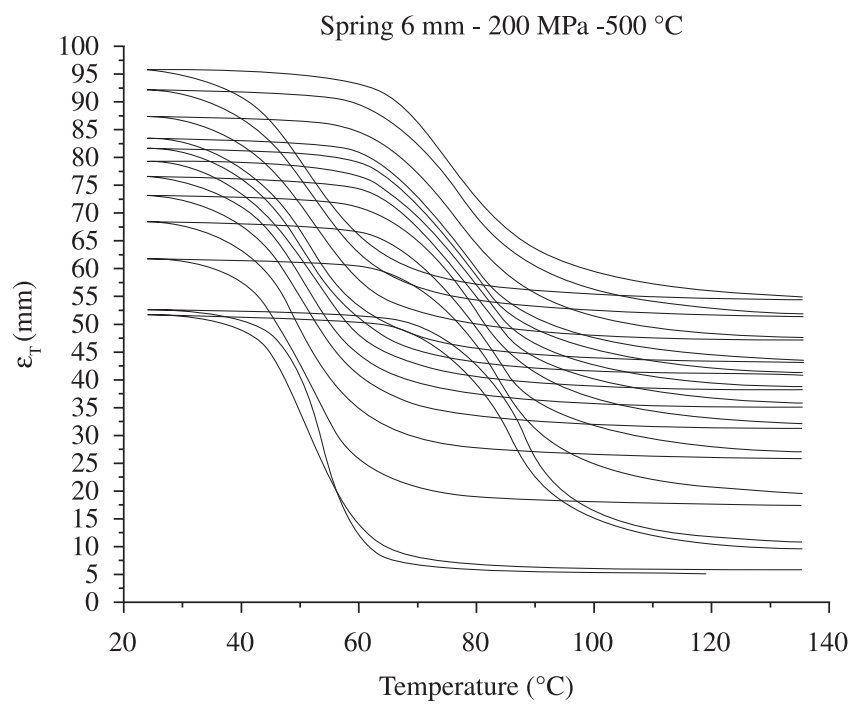

(d)

Figure 4. Strain vs. temperature curves obtained during training cycles under tensile stress: a) $70 \mathrm{MPa}$; b) $105 \mathrm{MPa}$; c) $170 \mathrm{MPa}$; and d) $200 \mathrm{MPa}$ (1, 2, 5, 10 , $20,30,40$ and $50^{\text {th }}$ cycles). 
increases proportionally with load applied. This is very close to the Clausius-Clapeyron relationship, on which the applied external stress increases the critical transformation temperatures ${ }^{16}$. Hysteresis loops of the strain vs. temperature curves developed changes to right and upward during thermal cycling, principally in the first five cycles. These evolutions are due to variants orientation process, facilitating the direct and reverse martensitic transformation (increase Ms and decrease As), therefore it's necessary less energy for transformation. Other characteristic in these curves is the presence of irrecoverable strain, which increase with applied load. A first factor is martensitic stabilization process by the excess of load that quickly and widely modifies the dislocations stress fields resulting in pinning or blocking of martensite variants. The second factor is due to introduction of microplastic deformation ${ }^{16,17}$.

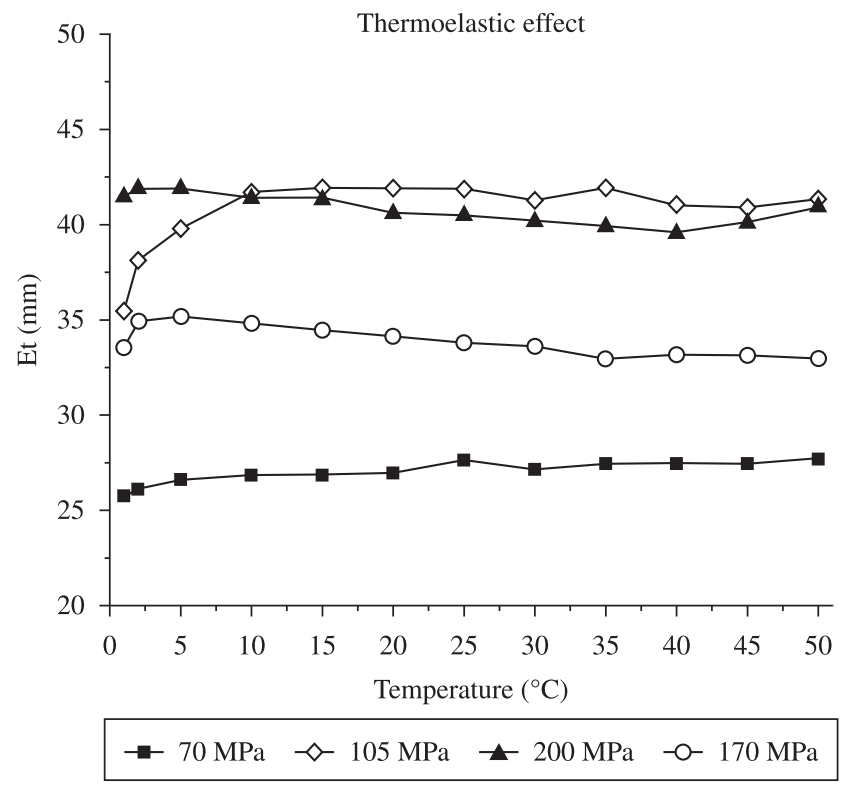

Figure 5. Evolution of thermoelastic strain with number of cycles for each tensile stress.

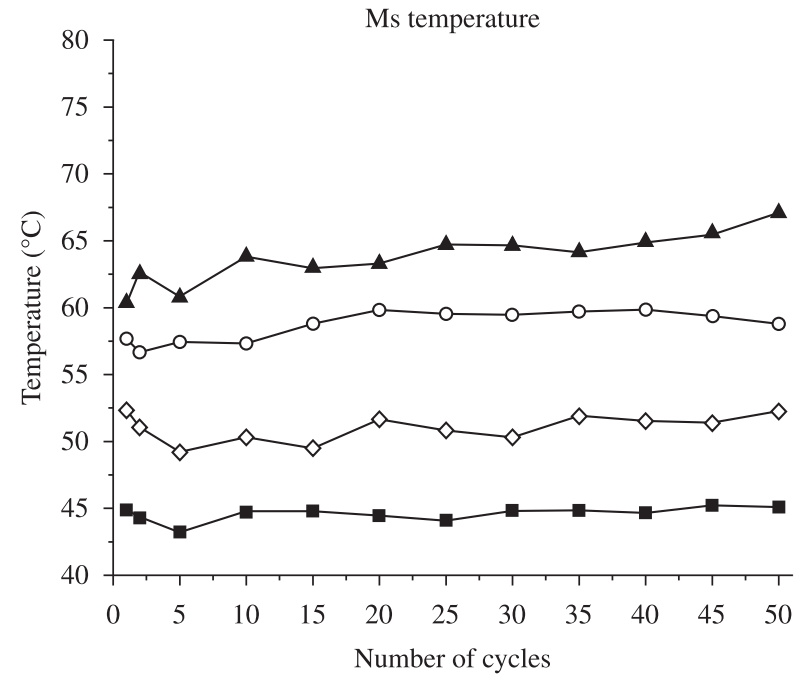

Figure 5 present the evolution of thermoelastic strain during thermal cycles for each applied tensile stress. Initially, the thermoelastic strains obtained increase with the load applied, but their evolutions during thermal cycles are different. For 70 and $105 \mathrm{MPa}$ stresses present a gradual increase during training cycles until practically to stabilize strain in the last cycles. For 170 and $200 \mathrm{MPa}$ stresses, the thermoelastic strain decrease continuously, after the two first initial cycles. During training occurs a martensite variants reorientation process where internal stresses generated by the dislocation fields becoming preferential some martensitic crystallographic variants, according to stress direction. For low and intermediate stresses, internal stress fields are formed gradually in each cycle, increasing thermoelastic strain during thermal cycling. In this sense, $105 \mathrm{MPa}$ stress presents best results, whereas 170 and $200 \mathrm{MPa}$ stresses produce a decrease of the thermoelastic strain because the internal stress fields (dislocation configuration) were saturated rapidly, inducing the martensitic stabilization. These behaviors were observed in cooper based shape memory alloy springs ${ }^{7}$.

Evolution of the $\mathrm{M}_{\mathrm{s}}$ and $\mathrm{A}_{\mathrm{s}}$ critical temperatures are presented in the Figure 6. The $M_{s}$ temperatures increase during thermal cycles due to martensite variants reorientation process. For this same reason, the $\mathrm{A}_{\mathrm{s}}$ temperatures decrease because reverse transformation is much easier, resulting in a thermal hysteresis small. For both evolutions, the temperatures become practically constant from twenty fifth cycle.

\subsection{Calorimetrical study in as-treated and training samples}

Calorimetric curve of sample heat treated at $500{ }^{\circ} \mathrm{C}$ for 24 hours, here in this section identified of as-treated sample, doesn't present the characteristic R-phase peak (Figure 3f). Also in the thermomechanical tests of the shape memory springs there isn't evidence of presence of the R-phase. In this section is presented a calorimetrical study in as-heat treated and training samples because this technique is more sensible to identify the R-phase. The second sample was obtained from memory spring training.

In the calorimetric tests, the samples were thermally cycled thirty times in a DSC apparatus, utilizing a temperature interval of 0 and $90{ }^{\circ} \mathrm{C}$ at a constant rate of $10^{\circ} \mathrm{C} / \mathrm{min}$. Figure 7 shows $1,5,10$, 15,20 and 30 calorimetrical curves for the as-treated sample. In the

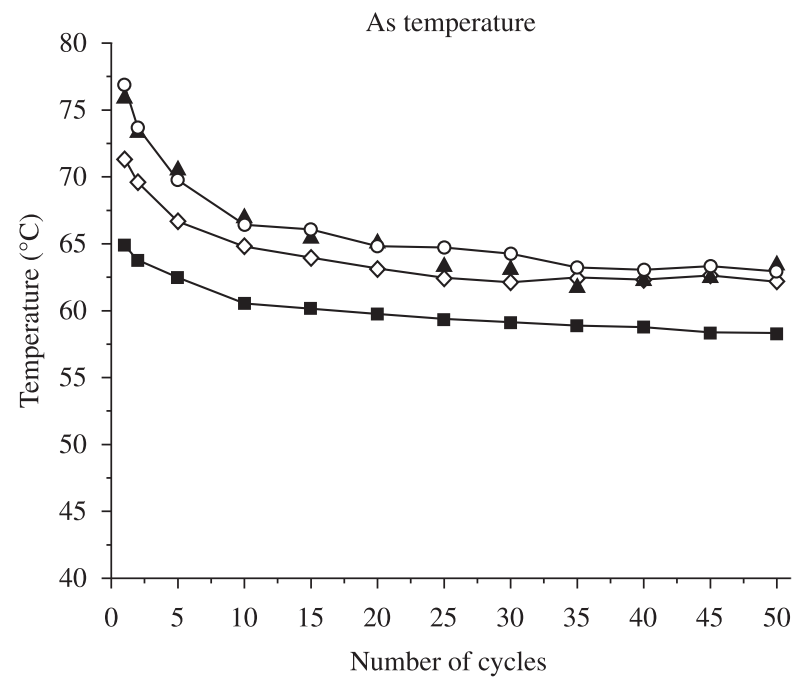

$70 \mathrm{MPa} \prec 105 \mathrm{MPa} \_200 \mathrm{MPa}-0-170 \mathrm{MPa}$

Figure 6. Temperature vs. number of cycle curves: a) Ms temperature and b) As temperature. 


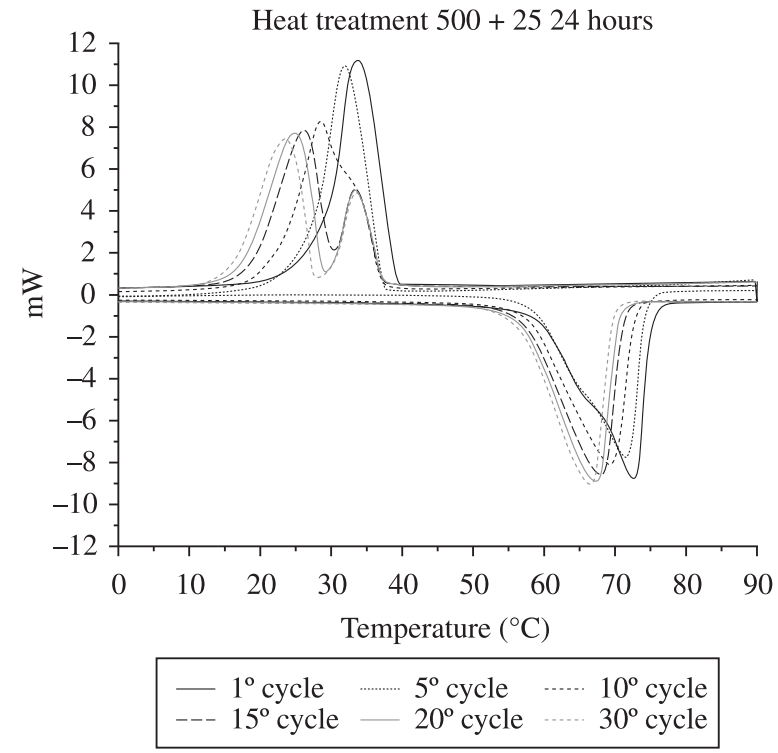

Figure 7. Calorimetrical cycles for the as-treated sample $\left(500^{\circ} \mathrm{C} / 24\right.$ hours $)$. Cycles: $1,5,10,15,20$ and $30^{\circ}$.

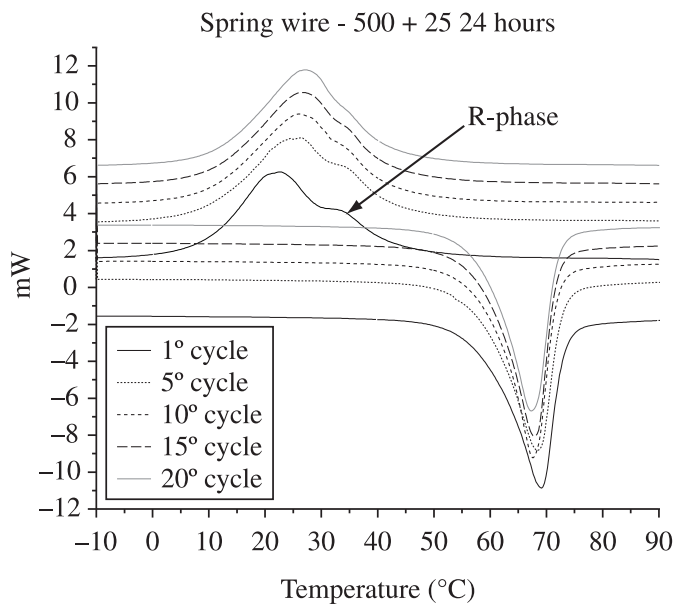

(a)

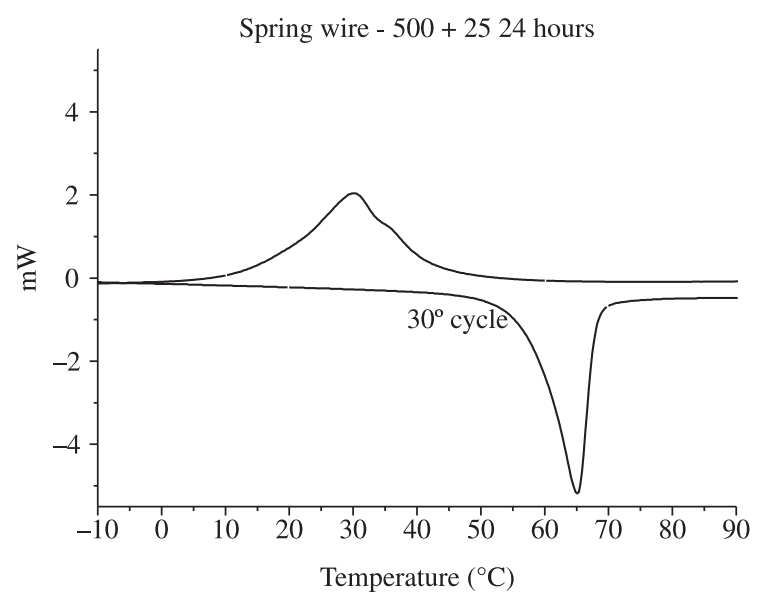

(b)

Figure 8. Calorimetrical cycles for training sample (135 MPa). a) Cycles: $1,5,10,15,20$ and b) $30^{\circ}$. tenth thermal cycle is possible to distinguish the formation of the $\mathrm{R}$-phase through a delay in the martensite peak (width peak increases). From tenth fifth cycle, martensitic transformation occurs clearly in a two-step transformation (B2 $\rightarrow \mathrm{R} \rightarrow \mathrm{B} 19^{\prime}$ ).

A DSC sample was prepared from a Ti-Ni spring utilized in the thermomechanical test at $135 \mathrm{MPa}$ (training sample). Figure 8 shows calorimetrical cycles in this sample. On the first cycles, the martensite phase is formed thought two-step transformation, undetectable in the thermomechanical tests, showing a large thermal hysteresis $\left(\mathrm{M}_{\mathrm{s}}-\mathrm{M}_{\mathrm{f}}=50^{\circ} \mathrm{C}\right)$.

In the case of the as-treat sample, precipitates were generated during heat treatment of 24 hours $\left(\mathrm{Ti}_{3} \mathrm{Ni}_{4}\right.$ precipitates). The interfacial strain energy stored among matrix phase (Ti-Ni) and precipitates benefits or induces the nucleation of martensite. This energy tends to decrease of intensity during thermal cycling due to accommodation or dissipation of these internal stresses.

Thus, the B19' martensitic transformation needs more free energy, resulting in decrease of transformation temperatures (Ms and Mf - Figure 7). As this energy is very large in comparison to R-phase transformation, environ two order of magnitude, B19' peak gradually leave of R-phase peak ${ }^{17,18}$. These differences among phase formation energies explain the passage for two-step transformation $^{19}$.

Trained sample calorimetrical curves show the presence quasi two-step transformation during initial thermal cycles (Figure 8 - curves 1 and 5). The handing in the occasion of manufacturing of the sample introduces some small deformation, resulting in appearance of R-phase. Preferential martensite variants orientation process occurs during thermomechanical test in the training sample. This process produced a configuration practically stable, even after the removal of load. After initial cycles, the transformation occurs in one step and general characteristics of transformation becomes unchangeable (temperatures, hysteresis and enthalpies), showing the efficacy of the training process under stress.

\section{Conclusions}

According to the obtained results can be concluded that:

- Heat Treatments applied in the Ti-Ni commercial wire produce important changes in the martensitic transformation thermoelastic properties. Samples treated at $400{ }^{\circ} \mathrm{C}$ always presented two-steps transformation (A - R - M), same after aged 24 hours. For samples treated at $600{ }^{\circ} \mathrm{C}$ always became transformation in an only step (A - M), independently of time. Samples treated at $500{ }^{\circ} \mathrm{C}$ showed an increase of the transformation critical temperatures, and after 12 hours, the $\mathrm{R}$-phase was suppressed. These samples are also more ductile in comparison the samples treated at $600^{\circ} \mathrm{C}$, due probably the large presence of precipitates.

- During thermomechanical tests in the Ti-Ni springs showed evolutions of the critical transformation temperatures but becomes stabilized from $25^{\circ}$ thermal cycle. Stress applied of better efficiency was at $105 \mathrm{MPa}$, presenting a thermoelastic strain of about $40 \mathrm{~mm}$.

- Thermal cycling studies by DSC in the treated $\left(500^{\circ} \mathrm{C} / 24\right.$ hours $)$ and trained samples showed that the R-phase is very sensitive the thermomechanical history of alloy. The first sample doesn't show the R-phase initially, but during thermal cycling this phase reappears. In the second case, the R-phase is inhibited due to stresses fields create during thermomechanical test, indicating to be the best method to avoid the presence of this phase. 


\section{Acknowledgments}

The authors would like to acknowledge the financial support and scholarships to this research project given by Brazilian agencies: Coordenação de Aperfeiçoamento de Pessoal de Nível Superior (CAPES), Conselho Nacional de Desenvolvimento Científico e Tecnológico $(\mathrm{CNPq})$ and Fundação de Amparo à Ciência e Tecnologia do Estado de Pernambuco (FACEPE).

\section{References}

1. Oliveira CAN, Gonzalez CH, De Araújo CJ, Pina EAC, Urtiga Filho S and Filho OOA. Caracterização do Efeito Memória de forma Reversível de Molas de Cu-Zn-Al. Revista Eletrônica de Materiais e Processos. 2009; 4.3:79-86.

2. Maeda S, Abe K, Yamamoto K, Tohyama O and Ito H. Active Endoscope With SMA (shape memory alloy) Coil Springs. Fundamental Research Department, 1996; 290-295.

3. Machado LG and Savi MA. Medical applications of shape memory alloys. Brazilian Journal of Medical and Biological Research. 2003; 683-691.

4. Corneliu M, Craciunescu, Jian Li and Manfred W. Contrained martensitic transformations in TiNiCu films. Thin Solid Films. 2003; 434(1-2):271-275.

5. Sittner P, Landa M, Luka's P and Nova'k V. R-phase transformation phenomena in thermo-mechanically loaded NiTi polycrystals. Mechanics of Materials, 2006; 38:475-492.

6. De Araújo, CJ, Silva E and Gonzalez CH. Thermal alarm using a shape memory alloy helical spring. In: Proceedings of the $16^{\text {th }}$ Brazilian Congress of Mechanical Engineering. 2005; Uberlândia, MG. p. 157-163.

7. Oliveira CAN, Gonzalez CH, Araújo CJ, Rocha JOS, Urtiga Filho, SL and Quadros NF. Thermoelastic characterization of Cu-Zn-Al shape memory Alloy spring actuators. In: $19^{\text {th }}$ International Congress of Mechanical Engineering. 2007; p. 137-151.
8. Paula AS, Canejo JPHG, Martins RMS and Braz Fernandes FM. Effect of thermal cyclin on the transformation temperature ranges of a Ni-Ti shape memory alloy. Materials Science \& Engineering A. 2004; 378:92-96.

9. Somsen CH, Zähres H, Kastner J, Kakeshita T and Saburi T. Influence of thermal annealing on the martensitic transitions in Ni-Ti shape memory alloys. Materials Science \& Engineering A. 1999; 310:273-275.

10. Nishida $\mathrm{M}$ and Honma T. All-round shape memory effect in Ni-Rich TiNi alloys generated by constrained aging. Scripta Metall. 1984; 18: 1293-98.

11. Liu Y and McCormick PG. Influence of Heat Treatment on the Mechanical Behaviour of a NiTi Alloy. ISIJ International. 1989; 5(29):417-422.

12. Honma I and Takei H. Effect of Heat Treatment on the Martensitic Transformation in TiNi Compound. Journal of Japan Institute of Metals. 1975; 39:175.

13. Miyazaki S, Otsuka K and Suzuki Y. Transformation pseudoelasticity and deformation behavior in a Ti-50.6at\% Ni alloy. Scripta Metallurgica. 1981; 15:287-292.

14. Ilczuk J. and Morawiec H. Internal Friction in Two-Stage Martensitic Transformation of Ni-Ti Alloy. Journal de Physique IV. 1996; 6:417. Supplement ao Journal de Physique III.

15. Otsuka K and Wayman CM. Shape Memory Materials. Cambridge: Cambridge University Press; 1998. p. 1-131.

16. Amengual A, Ceasari E and Romero R. On the Relationship Between Temperature and Critical Stress in the Two-Way Shape memory Effect of Cu-Zn-Al Single Crystals. Scripta Metallurgica et Materialia. 1995; 19:1269-1275.

17. Otsuka K and Ren X. Physical metallurgy of Ti-Ni-based shape memory alloys. Material Science. 2005; 50:511- 678.

18. Uchil J, Ganesh Kumara K and Mahesh KK. Effect of thermal cycling on R-phase stability in a Ni Ti shape memory alloy. Materials Science and Engineering A. 2002; 332:25-28.

19. Mahesh KK and Ganesh Kumara K. Electrical resistivity and strain recovery studies on the effect of thermal cycling under constant stress on R-phase in NiTi shape memory alloy. Physica B. 2002; 324:419-428. 
